\title{
Role of particle size in visible light photocatalysis of Congo Red using $\mathrm{TiO}_{2} \cdot\left[\mathrm{ZnFe}_{2} \mathrm{O}_{4}\right]_{x}$ nanocomposites
}

\author{
HIMANSHU NARAYAN*, HAILEMICHAEL ALEMU ${ }^{\dagger}$, LEBOHANG MACHELI ${ }^{\dagger}$, \\ MANTOA SEKOTA ${ }^{\dagger}$, MADHAVI THAKURDESAI ${ }^{\dagger \dagger}$ and $\mathbf{T}$ K GUNDU RAO ${ }^{\#}$ \\ Department of Physics and Electronics, ${ }^{\dagger}$ Department of Chemistry and Chemical Technology, \\ National University of Lesotho, Roma 180, Lesotho \\ ${ }^{\dagger \dagger}$ Department of Physics, Birla College, Kalyan 421 304, India

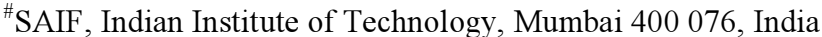

MS received 16 September 2008

\begin{abstract}
TiO}_{2} \cdot\left[\mathrm{ZnFe}_{2} \mathrm{O}_{4}\right]_{x}(x=0 \cdot 0-0 \cdot 5)$ nanocomposites (NCs) with an average particle size of $72 \cdot 4 \mathrm{~nm}$ were synthesized by the method of co-precipitation/hydrolysis (CPH). For the comparison of particle-size dependent effects, a set of polycrystalline samples with similar compositions was also prepared by solid state reaction (SSR) route. Average particle size for SSR prepared samples was about 3.0 $\mu \mathrm{m}$. All the samples were characterized using scanning electron microscopy (SEM), X-ray diffraction (XRD), particle size analyzer, Raman spectroscopy and Fourier transform infra-red (FTIR) spectroscopy. Their visible light photocatalytic activity was tested for the degradation of Congo Red dye. Maximum photodegradation was observed for the NC with $x=0 \cdot 1$ synthesized by CPH (particle size, $71 \mathrm{~nm}$ ). Similar composition prepared by SSR method (particle size, $6.19 \mu \mathrm{m}$ ) showed lower photoactivity in comparison even with that observed for pure $\mathrm{TiO}_{2}$ (particle size, $4.03 \mu \mathrm{m}$ ). It was, therefore, concluded that enhanced photodegradation is directly related to the reduced particle size of the composites, which implies that photosensitization is the process primarily involved. Although, doping of $\mathrm{TiO}_{2}$ with $\mathrm{ZnFe}_{2} \mathrm{O}_{4}$ does extend the cut-off wavelength towards visible parts of the spectrum, its contribution in the enhancement is not as significant as that due to the photosensitization.
\end{abstract}

Keywords. Titanium dioxide; nanocomposite; photocatalysis.

\section{Introduction}

In recent years, titanium dioxide $\left(\mathrm{TiO}_{2}\right)$ based nanomaterials and nanocomposites have attracted much interest of the materials scientists all around the world mainly because of their interesting optical and electronic properties as well as their potential use in photocatalysis (Bumpas et al 1999; Yuan and Zhang 2001; Cheng et al 2004; Liu et al 2004; Dung et al 2005; Wade 2005; Wahi et al 2005; Khan et al 2006; Srinivasan et al 2006; Habibi et al 2007). The applications of $\mathrm{TiO}_{2}$ as a photocatalyst are favoured by the low cost, chemical stability, nontoxicity and high photocatalytic reactivity. Semiconductor $\mathrm{TiO}_{2}$ has a wide bandgap of about $3.2 \mathrm{eV}$, which can facilitate the UV-activated (wavelength, $<390 \mathrm{~nm}$ ) photocatalysis, generally required for the removal of aqueous contamination by photochemical degradation of contaminates (Bumpas et al 1999; Dung et al 2005; Wade 2005; Wahi et al 2005; Khan et al 2006; Srinivasan et al 2006; Habibi et al 2007). Since the treatment costs can be further reduced by efficiently utilizing solar light as the source of

*Author for correspondence (h.narayan@nul.ls) excitation, extensive efforts are currently underway to develop $\mathrm{TiO}_{2}$ based photocatalysts that are not only capable of supporting visible light activated photodegradation, but also possess improved photocatalytic reactivity as compared to that of the pure material. To plan and synthesize such photocatalysts, a good understanding of the processes involved is necessary.

Two mechanisms have been proposed for the $\mathrm{TiO}_{2}$ mediated photocatalytic oxidation process (Bumpas et al 1999): (i) Upon irradiation with suitable wavelengths, electrons from the valence band of $\mathrm{TiO}_{2}$ get excited to the conduction band. 'Holes' thus generated on the surface of the material react with oxygen, water and hydroxide ions to form hydroxyl radicals. On the other hand, excited electrons react with oxygen molecules to form superoxides and perhydroxyl radicals. The highly active oxygen species thus formed, react with the pollutants leading to their degradation and (ii) the pollutant (e.g. dye) molecules adsorbed to the $\mathrm{TiO}_{2}$ particles absorb visible radiations, get photochemically excited, and transfer an electron to the semiconductor particle. The latter, in turn reduces molecular oxygen to form superoxide anion radical. At the same time, a cation radical is produced from the pollutant, which may lead to the degradation of other pol- 
lutant molecules. This mechanism is referred to as photosensitization.

Clearly, the first mechanism is based on the energy gap of the catalyst, whereas the second one, on the total effective surface area (where the pollutant molecules could be adsorbed), and therefore, on the particle size of the semiconductor. Moreover, the UV irradiation plays a significant role in the first mechanism as $\mathrm{TiO}_{2}$ absorbs in that region, whereas in the second mechanism, visible light irradiation may become more important since the pollutant molecules, such as dyes, adsorbed on the semiconductor surface, absorb in the visible regions.

In view of above mentioned points, the photocatalytic activity of $\mathrm{TiO}_{2}$ may be improved by two methods. First, an appropriate method of synthesis can be chosen, which can produce materials with larger effective surface area, i.e. particles with reduced size, preferably within a few tens of nanometers, or even less. Along this line, several $\mathrm{TiO}_{2}$ based nano-materials (nano-structures and nanocomposites) have been synthesized for photocatalytic applications (Bumpas et al 1999; Dung et al 2005; Wahi et al 2005; Khan et al 2006; Habibi et al 2007). On the other hand, the bandgap of the host $\mathrm{TiO}_{2}$ can be narrowed by suitable doping so as to enable the utilization of larger parts of spectrum, e.g. by extending the photo-response from UV to the visible regions (wavelengths $>400 \mathrm{~nm}$ ). For instance, the $n$-type $\mathrm{ZnFe}_{2} \mathrm{O}_{4}$ with a narrow bandgap of about $1.9 \mathrm{eV}$ is a suitable dopant for irradiation wavelengths shorter than $650 \mathrm{~nm}$ (Wade 2005). Doping of $\mathrm{TiO}_{2}$ with $\mathrm{ZnFe}_{2} \mathrm{O}_{4}$ is expected to extend the photoresponse of the former towards the visible regions of the spectrum with the additional advantage that the co-doping of $\mathrm{Zn}^{+2}$ and $\mathrm{Fe}^{+3}$ ions suppresses the undesired recombination of photo-generated electrons with the holes $\left(e^{-} / h^{+}\right.$recombination) (Liu et al 2004; Wade 2005; Srinivasan et al 2006).

Better photocatalytic activity of $\mathrm{TiO}_{2}-\mathrm{ZnFe}_{2} \mathrm{O}_{4}$ composites as compared to that of pure $\mathrm{TiO}_{2}$ has been reported by several authors, in connection with the photodegradation of phenol (Yuan and Zhang 2001; Wade 2005; Srinivasan et al 2006), Rhodamine B (Liu et al 2004), and methyl orange (Cheng et al 2004). In most of the published works, however, it is apparently presumed that the first mechanism-band gap modification-is responsible for the increased photocatalytic activity of the material (Yuan and Zhang 2001; Wade 2005; Srinivasan et al 2006). Only a few reports have considered the possibility of effective surface area-, or the particle size-dependent photosensitization playing a role in the enhancement (Cheng et al 2004). Interestingly, Liu et al (2004) did measure the particle size, but associated the observed photoactivity with anatase to rutile transformation and the calcination temperatures.

In the present work, we try to investigate the role of particle size in the photocatalytic activity of $\mathrm{TiO}_{2}$. $\left[\mathrm{ZnFe}_{2} \mathrm{O}_{4}\right]_{x}$ materials in the degradation of the dye Congo
Red (CR). Two different ranges of particle size were obtained by employing two methods of sample preparation: the coprecipitation/hydrolysis $(\mathrm{CPH})$ to synthesize nano-particles; and the solid-state reaction (SSR) route to produce particles within a few micrometers.

\section{Experimental}

\subsection{Material synthesis}

Nanocomposites were prepared by CPH synthesis method (Srinivasan et al 2006) for the formation of $\mathrm{TiO}_{2}$. $\left[\mathrm{ZnFe}_{2} \mathrm{O}_{4}\right]_{x}$ with $x$ (mole fraction) values of $0 \cdot 1,0 \cdot 2$, $0.3,0.4$ and 0.5 . The chemicals used in this work were $\mathrm{Fe}\left(\mathrm{NO}_{3}\right)_{3} \cdot 9 \mathrm{H}_{2} \mathrm{O}$ and $\mathrm{Zn}\left(\mathrm{NO}_{3}\right)_{2} \cdot 4 \mathrm{H}_{2} \mathrm{O}$ (HOLPRO ANALYTICS, SA), n-propanol (BDH), iso-propanol (UNILAB, SA), tetrabutyl-orthotitanate (Fluka), Congo Red (Aldrich Chemical Co.) and nitric acid (ACE, SA). $\mathrm{ZnFe}_{2} \mathrm{O}_{4}$ was first precipitated using appropriate quantities of $\mathrm{Fe}\left(\mathrm{NO}_{3}\right)_{3} \cdot 9 \mathrm{H}_{2} \mathrm{O}$ and $\mathrm{Zn}\left(\mathrm{NO}_{3}\right)_{2} \cdot 4 \mathrm{H}_{2} \mathrm{O}$ in isopropyl alcohol in which the mixture was heated at $65^{\circ} \mathrm{C}$ and stirred for $30 \mathrm{~min}$. To co-precipitate the nitrate precursor, $\mathrm{pH}$ of the solution was raised to 6.5 by slowly adding a $3.5 \mathrm{M} \mathrm{NH}_{4} \mathrm{OH}$ solution using isopropyl alcohol as the solvent. Approximately $10 \mathrm{~g}$ of distilled and deionized water was then added drop wise to the solution and was stirred for $45 \mathrm{~min}$. A solution of tetrabutyl-orthotitanate $\left(\mathrm{Ti}(\mathrm{OBu})_{4}\right)$ and isopropyl alcohol was prepared in a ratio of $1: 2$ by weight and added drop wise to the coprecipitated $\mathrm{ZnFe}_{2} \mathrm{O}_{4}$ solution for controlled hydrolysis with $\mathrm{H}_{2} \mathrm{O}: \mathrm{Ti}(\mathrm{OBu})_{4}$ in the ratio of $25: 1$. The final solution was kept stirred at $65^{\circ} \mathrm{C}$ for $90 \mathrm{~min}$, filtered, and then dried at 100 and $220^{\circ} \mathrm{C}$, respectively. The prepared $\mathrm{TiO}_{2} \cdot\left[\mathrm{ZnFe}_{2} \mathrm{O}_{4}\right]_{x}$ nanoparticles were then calcined in a flowing air atmosphere at $500^{\circ} \mathrm{C}$ for $3 \mathrm{~h}$.

Polycrystalline $\mathrm{TiO}_{2} \cdot\left[\mathrm{ZnFe}_{2} \mathrm{O}_{4}\right]_{x}$ materials were also prepared using the solid-state reaction [SSR] method. Highly pure $(99.9 \%) \mathrm{TiO}_{2}$, predominantly rutile (Aldrich) with $\mathrm{Fe}\left(\mathrm{NO}_{3}\right)_{3} \cdot 9 \mathrm{H}_{2} \mathrm{O}$ and $\mathrm{Zn}\left(\mathrm{NO}_{3}\right)_{2} \cdot 4 \mathrm{H}_{2} \mathrm{O}$ of different molar ratios $(x=0 \cdot 1,0 \cdot 2,0 \cdot 3,0.4$ and 0.5$)$ were mixed in ethanol solution and ground in an agate mortar for $1 \mathrm{~h}$. The mixture was dried at $60^{\circ} \mathrm{C}$ for $1 \mathrm{~h}$, followed by calcinations at different temperatures for $2 \mathrm{~h}$. Both sets of samples were then characterized with a number of instrumental analysis techniques.

\subsection{Measurements}

Scanning electron microscopy (SEM) of all the samples was carried out using a Jeol JSM5600 machine. The powder X-ray diffraction (XRD) measurements were done on a Shimadzu D6000 diffractometer (Shimadzu, Japan) using $\mathrm{Cu}-\mathrm{K} \alpha$ radiation $(\lambda=1.5406 \AA)$. The particle size distribution of the nanocomposites was measured as water suspension using a Microtrac/Nanotrac TM150 
particle size analyzer which employs optical light scattering measurements equipped with Microtrac FLEX software. Raman spectra were recorded using a LabRAM HR machine from Jobin Yvon, with the $514 \mathrm{~nm}$ green excitation light (Laser output: $20 \mathrm{~mW}$ ). The FTIR spectra of the samples were obtained with a Nicolet MAGNA-IR 760 Spectrometer in the range $4000-400 \mathrm{~cm}^{-1}$. For FTIR, pellets of the samples were prepared using $\mathrm{KBr}$.

The visible-light photoactivity was carried out using an inexpensive photoreactor (schematic diagram shown in figure 1) consisting of a heavy duty 1 litre glass beaker into which was placed a magnetic stirring bar and a $500 \mathrm{ml}$ conical glass vessel that separated the light source from water (Bumpas et al 1999). A $10 \mathrm{~cm}$ ring attached to a ring stand was fitted on top of the conical glass vessel to hold it in place inside the beaker, which was placed on a magnetic stirrer. After addition of $50 \mathrm{ml}$ of dye containing water and $\mathrm{TiO}_{2} \cdot\left[\mathrm{ZnFe}_{2} \mathrm{O}_{4}\right]_{x}$ to the 1 litre beaker, the conical glass vessel was sealed with parafilm where it touched the top of the beaker. Finally, a $60 \mathrm{~W}$ fluorescent lamp (Phillips) was placed in the middle of this vessel so that it could not touch the sides and its end was $\sim 2 \mathrm{~cm}$ from the bottom of this vessel. The fluorescent lamp was held in place by a 3-pronged clamp. A solution $(850 \mathrm{ml})$ containing $25 \mathrm{mg}$ of Congo Red per litre of water, a stirring bar, and $275 \mathrm{mg}$ of $\mathrm{TiO}_{2} \cdot\left[\mathrm{ZnFe}_{2} \mathrm{O}_{4}\right]_{x}$ was placed in the photoreactor as described. The fluorescent lamp was turned on and the solution was stirred throughout the duration of the experiment. At predetermined times, $1.5 \mathrm{ml}$ of the solution was removed and centrifuged. The clear solution was taken and its absorbance was measured at $498 \mathrm{~nm}$ using a UV-Vis Shimadzu model 1201 spectrophotometer. The absorbance of the Congo Red solutions in the presence of $\mathrm{TiO}_{2} \cdot\left[\mathrm{ZnFe}_{2} \mathrm{O}_{4}\right]_{x}$, without light, and, with light but in the absence of $\mathrm{TiO}_{2} \cdot\left[\mathrm{ZnFe}_{2} \mathrm{O}_{4}\right]_{x}$, were also

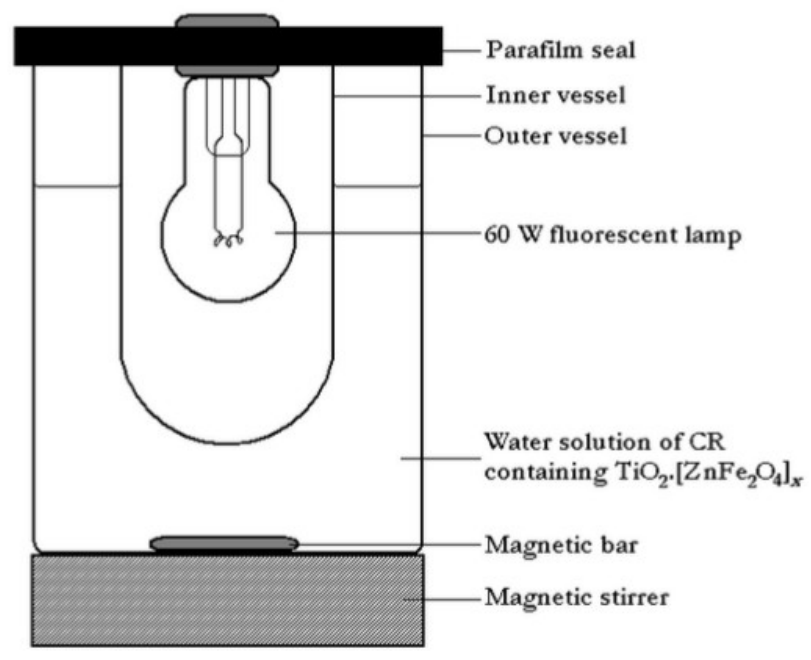

Figure 1. A schematic diagram (not to scale) of the photoreactor used in the present work. measured to see the dependence of degradation of the dye in the presence of catalyst and light alone, respectively. The photocatalytic properties of the polycrystalline $\mathrm{TiO}_{2}$. $\left[\mathrm{ZnFe}_{2} \mathrm{O}_{4}\right]_{x}$ materials (SSR prepared) for the decomposition of Congo Red under visible light irradiation were also measured.

\section{Results and discussion}

\subsection{Particle size analysis}

The SEM pictures (a typical one depicted in figure 2) of $\mathrm{CPH}$ synthesized $\mathrm{TiO}_{2} \cdot\left[\mathrm{ZnFe}_{2} \mathrm{O}_{4}\right]_{x}$ NCs show small grains of $\sim 70 \mathrm{~nm}$ size. Figure 3 shows the XRD results for $\mathrm{CPH}$ synthesized $\mathrm{TiO}_{2} \cdot\left[\mathrm{ZnFe}_{2} \mathrm{O}_{4}\right]_{x} \mathrm{NCs}$ with $x=0 \cdot 1$ to $x=0.5$ compositions. The spectra for crystalline $\mathrm{TiO}_{2}$ (both anatase and rutile phases), $\mathrm{ZnO}$ (wurtzite) and $\mathrm{Fe}_{2} \mathrm{O}_{3}$ (haematite) are also shown along with those for similar compositions of the polycrystalline samples prepared by SSR route, to facilitate proper identification of the peaks.

Crystalline nature of the samples prepared by SSR process is evidenced by the sharp peaks. With the increasing value of $x$ in these samples, a gradual decrease of rutile phase is revealed by the decreasing heights of the $2 \theta=27.4^{\circ}(110), 36.1^{\circ}(101), 39.2^{\circ}(200), 54.3^{\circ}$ (211), 56.6 $6^{\circ}(220)$ and $69 \cdot 0^{\circ}(301)$ peaks. Similarly, the increasing ratios of $\mathrm{ZnO}$ and $\mathrm{Fe}_{2} \mathrm{O}_{3}$ are indicated by the gradually increasing heights of the corresponding peaks with increasing $x$. More clearly, this is evident, for example, from the $2 \theta=31.8^{\circ}(100)$, and $34.5^{\circ}(002)$ peaks of $\mathrm{ZnO}$ (Ghosh and Raychaudhuri 2007), and 33.6 (104) peak of $\mathrm{Fe}_{2} \mathrm{O}_{3}$ ( $\mathrm{Li}$ et al 2007).

On the other hand, the XRD patterns for the CPH synthesized composites show broadening of the prominent peaks indicating directly to the reduced size of the particles. This is confirmed from the results of crystallite size calculated from XRD data as discussed in the next section. Secondly, in all the composites prepared by $\mathrm{CPH}$, the most prominent peak at $2 \theta=25.7^{\circ}$ clearly corresponds to the (101) peak of the anatase phase of $\mathrm{TiO}_{2}$. Significant presence of other anatase peaks, although most of them highly broadened, and/or some merged with the peaks of other phases (e.g. $2 \theta=37.5^{\circ}(103), 38.4^{\circ}$ (004), 39.2 ${ }^{\circ}(112), 48 \cdot 0^{\circ}(200), 54 \cdot 8^{\circ}(105), 54 \cdot 9^{\circ}$ (121) (211) and $\left.63 \cdot 1^{\circ}(213)(123)\right)$, also point towards the presence of this phase in the $\mathrm{CPH}$ synthesized composites. Interestingly, the presence of rutile phase of $\mathrm{TiO}_{2}$, peaking mainly at $2 \theta=27 \cdot 6^{\circ}$ (110) is evident only in one composite $(x=0.4)$ prepared by this method. Moreover, traces of $\mathrm{ZnTiO}_{3}\left(\right.$ peak at $\left.2 \theta=33 \cdot 3^{\circ}\right)$ and spinel $\mathrm{ZnFe}_{2} \mathrm{O}_{4}$ (at $2 \theta=63 \cdot 0^{\circ}$ ) are also present in the composites (Wade 2005).

The FWHM of the Gaussian best-fit to the prominent peaks in the XRD data was used to estimate the crystallite (defined as the smallest regions of the sample that diffract 
the incident X-rays coherently) size of each sample using the Debye-Scherrer formula (Boulc'h et al 2001; Wahi et al 2005; Habibi et al 2007). An average crystallite size of $51.8 \mathrm{~nm}$ was found for the samples prepared by SSR route, which is comparable to the size of $51.6 \mathrm{~nm}$ of the main constituent rutile $\mathrm{TiO}_{2}$. On the other hand, the average crystallite size for the composites prepared by $\mathrm{CPH}$ was estimated to be $29.3 \mathrm{~nm}$ indicating that the samples prepared by this method are indeed nanometer-sized composites (see table 1).

The distribution of number of particles with size determined by the particle size analyser is shown in figure 4. From these data, the grain size of $\mathrm{CPH}$ synthesized composites was found to be almost uniform (within the range $43-86 \mathrm{~nm}$ ) with an average value of $72.4 \mathrm{~nm}$, which is comparable with that measured from the SEM pictures. The grain size for the samples prepared by SSR route was found to range from $0.24-6.54 \mu \mathrm{m}$, with an average value around $3.0 \mu \mathrm{m}$. Although, the average grain size decreased with $x$ up to $x=0.4$ (for $x=0 \cdot 5$, it increased again) for this set of samples, it was not clear whether $\mathrm{ZnFe}_{2} \mathrm{O}_{4}$ doping was responsible for this decrease as claimed by Liu et al (2004), because crystallite size data (from XRD) for both sets of samples, and average grain size of $\mathrm{CPH}$ synthesized samples do not show any such trend (see table 1). The average grain size of the commercial $\mathrm{TiO}_{2}$ was also estimated and found to be about $4.03 \mu \mathrm{m}$.

A comparison between the crystallite size (determined by $\mathrm{XRD}$ ) and the grain size (measured by particle size analyser) seems to reveal that about 50 crystallites combine during SSR process to form one grain, whereas, only 2-3 crystallites apparently make each of the grains in the $\mathrm{CPH}$ method. The obvious reason for this difference is the larger time available during the solid state reaction that facilitates more agglomeration.

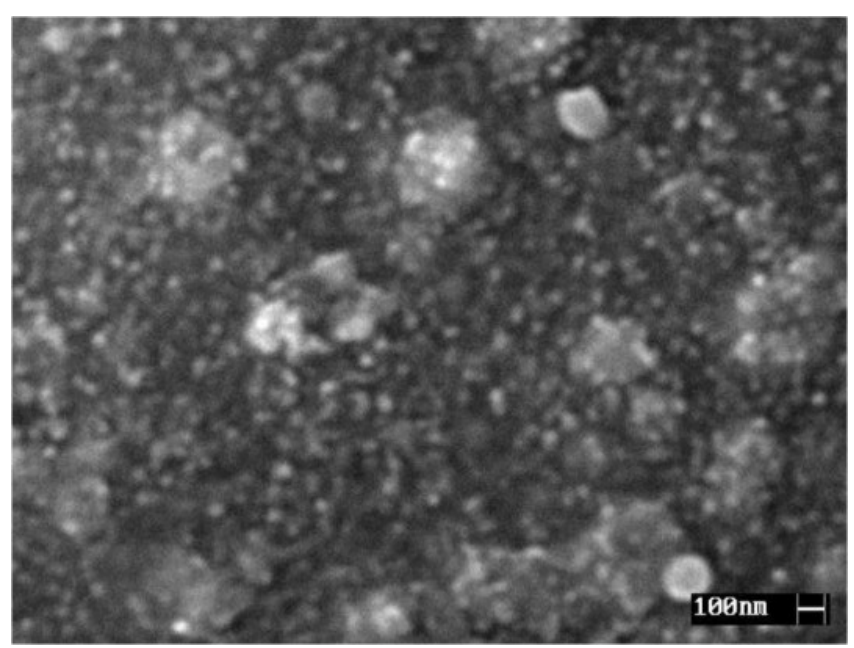

Figure 2. A typical SEM picture of $\mathrm{CPH}$ synthesized $\mathrm{TiO}_{2} \cdot\left[\mathrm{ZnFe}{ }_{2} \mathrm{O}_{4}\right]_{x}$ nanocomposite (for $x=0 \cdot 1$ composition).

\subsection{Raman and FTIR spectroscopy}

The Raman spectra for various compositions of the $\mathrm{CPH}$ synthesized NCs are shown in figure 5. In a typical Raman spectrum, the anatase phase of nanosized $\mathrm{TiO}_{2}$ is known to show five distinct peaks at 151, 196, 409, 515 and $633 \mathrm{~cm}^{-1}$, assigned to the $E_{\mathrm{g}}, E_{\mathrm{g}}, B_{1 \mathrm{~g}}, A_{1 \mathrm{~g}}$ or $B_{1 \mathrm{~g}}$ and $E_{\mathrm{g}}$ modes, respectively (Zhang et al 2000). Qualitatively, the Raman profiles obtained for our samples do indicate that anatase phase is the main constituent in all the NCs, although the peaks corresponding to the 151 and $409 \mathrm{~cm}^{-1}$ are slightly redshifted to around 145 and $395 \mathrm{~cm}^{-1}$, respectively. The occurrence of such shifts has been discussed in detail by Zhang et al (2000) within the framework of a phonon confinement model, and has been attributed to the crystallite size of the samples. It has been reported that with decreasing crystallite size, the lowest frequency $E_{\mathrm{g}}$ mode peak gradually blueshifts, and for a crystallite size of about $27.9 \mathrm{~nm}$, it is expected to

\section{$\mathrm{TiO}_{2} \cdot\left[\mathrm{ZnFe}_{2} \mathrm{O}_{4}\right]_{x}$}

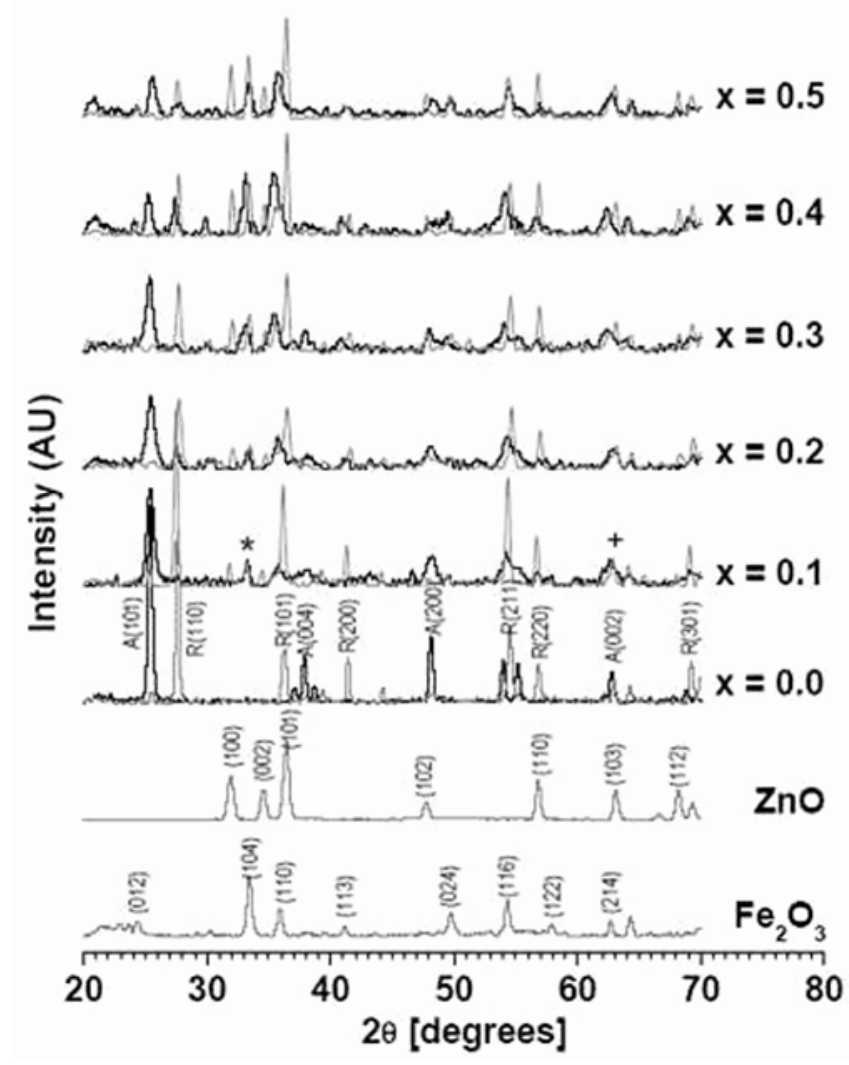

Figure 3. X-ray diffraction patterns for various compositions of the $\mathrm{TiO}_{2} \cdot\left[\mathrm{ZnFe}_{2} \mathrm{O}_{4}\right]_{x} \mathrm{NC}$ with $x=0.0$ (pure $\mathrm{TiO}_{2}$, dark line for anatase and gray line for rutile phase) to $x=0 \cdot 5$, along with those for pure $\mathrm{ZnO}$ (wurtzite phase) and $\mathrm{Fe}_{2} \mathrm{O}_{3}$ (haematite phase). For the composites, dark lines correspond to the samples prepared by $\mathrm{CPH}$ synthesis, and gray lines to those prepared by the SSR route. $\left\{*: \mathrm{ZnTiO}_{3}\right.$ phase $\left(2 \theta=33 \cdot 3^{\circ}\right)$; +: spinel $\mathrm{ZnFe}_{2} \mathrm{O}_{4}$ phase $\left.\left(2 \theta=63 \cdot 0^{\circ}\right)\right\}$ 
Table 1. Particle size.

\begin{tabular}{|c|c|c|c|}
\hline Sample & $\begin{array}{l}\text { Preparation } \\
\text { method }\end{array}$ & $\begin{array}{l}\text { Mean crystallite size* } \\
\text { from XRD }(\mathrm{nm})\end{array}$ & $\begin{array}{c}\text { Mean grain size* } \\
\text { from size analyser }(\mu \mathrm{m})\end{array}$ \\
\hline Rutile & As received & $51 \cdot 6$ & 4.03 \\
\hline Anatase & As received & $57 \cdot 1$ & - \\
\hline $\mathrm{TiO}_{2} \cdot\left[\mathrm{ZnFe}_{2} \mathrm{O}_{4}\right]_{0 \cdot 1}$ & SSR & $56 \cdot 5$ & $6 \cdot 19$ \\
\hline $\mathrm{TiO}_{2} \cdot\left[\mathrm{ZnFe}_{2} \mathrm{O}_{4}\right]_{0.2}$ & SSR & $40 \cdot 1$ & $3 \cdot 23$ \\
\hline $\mathrm{TiO}_{2} \cdot\left[\mathrm{ZnFe}_{2} \mathrm{O}_{4}\right]_{0.3}$ & SSR & $54 \cdot 9$ & $1 \cdot 19$ \\
\hline $\mathrm{TiO}_{2} \cdot\left[\mathrm{ZnFe}_{2} \mathrm{O}_{4}\right]_{0 \cdot 4}$ & SSR & $53 \cdot 8$ & $0 \cdot 96$ \\
\hline $\mathrm{TiO}_{2} \cdot\left[\mathrm{ZnFe}_{2} \mathrm{O}_{4}\right]_{0.5}$ & SSR & $53 \cdot 9$ & $3 \cdot 60$ \\
\hline Average: & SSR & $51 \cdot 8$ & 3.03 \\
\hline $\mathrm{TiO}_{2} \cdot\left[\mathrm{ZnFe}_{2} \mathrm{O}_{4}\right]_{0 \cdot 1}$ & $\mathrm{CPH}$ & $28 \cdot 9$ & $0 \cdot 071$ \\
\hline $\mathrm{TiO}_{2} \cdot\left[\mathrm{ZnFe}_{2} \mathrm{O}_{4}\right]_{0 \cdot 2}$ & $\mathrm{CPH}$ & $29 \cdot 2$ & 0.075 \\
\hline $\mathrm{TiO}_{2} \cdot\left[\mathrm{ZnFe}_{2} \mathrm{O}_{4}\right]_{0.3}$ & $\mathrm{CPH}$ & $29 \cdot 5$ & $0 \cdot 077$ \\
\hline $\mathrm{TiO}_{2} \cdot\left[\mathrm{ZnFe}_{2} \mathrm{O}_{4}\right]_{0 \cdot 4}$ & $\mathrm{CPH}$ & $29 \cdot 4$ & $0 \cdot 072$ \\
\hline $\mathrm{TiO}_{2} \cdot\left[\mathrm{ZnFe}_{2} \mathrm{O}_{4}\right]_{0.5}$ & $\mathrm{CPH}$ & - & $0 \cdot 067$ \\
\hline Average: & $\mathrm{CPH}$ & $29 \cdot 3$ & $0 \cdot 072$ \\
\hline
\end{tabular}

*Because of the difference of probes used (diffraction of X-rays in XRD and scattering of optical light in particle size analyser), the crystallite- and grain-size have different meanings. Crystallites are presumably the small regions within a grain that diffract the X-rays coherently. Thus, a grain could have several crystallites within itself.

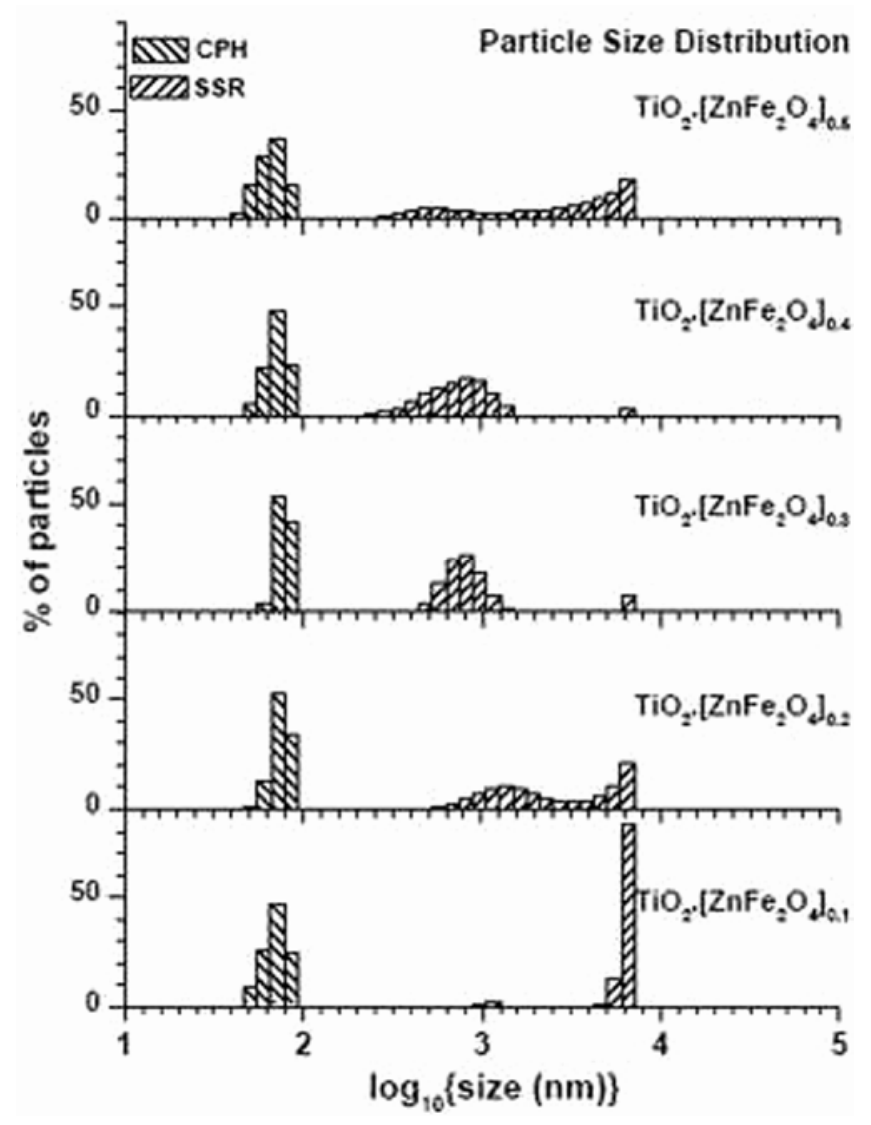

Figure 4. Particle size distribution for various compositions of the $\mathrm{TiO}_{2} \cdot\left[\mathrm{ZnFe}_{2} \mathrm{O}_{4}\right]_{x}$ samples prepared by $\mathrm{CPH}$ and by the SSR method.

peak around $145 \mathrm{~cm}^{-1}$. This argument satisfactorily explains the redshifts observed in our measurements on the samples with crystallite size of $29.3 \mathrm{~nm}$. Further, the nearly constant value of the crystallite size for all composites is also in line with the almost fixed positions of the peaks for all compositions. Interestingly, the Raman spectrum of the NC with $x=0.4$ does not show the appearance of any significant peaks around 450 and $610 \mathrm{~cm}^{-1}$, corresponding to the rutile phase, whose presence was evidenced in the XRD results of this composition. This is probably due to the fact that Raman measurements probe the samples only locally, whereas XRD usually gives averaged data about the structure over several unit cells. Apart from these observations, the contribution of $\mathrm{ZnO}$ and $\mathrm{Fe}_{2} \mathrm{O}_{3}$ phases is apparently negligible in the Raman spectra of all NCs.

Figure 6 shows the FTIR spectra of pure $\mathrm{TiO}_{2}$ and $\mathrm{CPH}$ synthesized $\mathrm{TiO}_{2} \cdot\left[\mathrm{ZnFe}_{2} \mathrm{O}_{4}\right]_{0 \cdot 1}$. Pure $\mathrm{TiO}_{2}$ exhibits a very intense sharp peak in the region of $485 \mathrm{~cm}^{-1}$, which is due to $\mathrm{Ti}-\mathrm{O}$ vibration in the rutile phase of $\mathrm{TiO}_{2}$. The peak observed around $432 \mathrm{~cm}^{-1}$ is characteristic of Ti-O in the anatase phase (Busani and Devine 2005). In the FTIR spectrum of the CPH synthesized $\mathrm{TiO}_{2} \cdot\left[\mathrm{ZnFe}_{2} \mathrm{O}_{4}\right]_{0 \cdot 1}$ (figure 6), these peaks have shifted slightly towards higher wavenumbers. These shifts may be attributed to $\mathrm{Ti}-\mathrm{O}$ vibrations in a changed environment resulting from the presence of $\mathrm{ZnFe}_{2} \mathrm{O}_{4}$ in $\mathrm{TiO}_{2}$ lattice.

Upon doping with $\mathrm{ZnFe}_{2} \mathrm{O}_{4}$, no significant changes were observed in the FTIR spectra apart from small peakshifts, especially at lower concentrations of the dopant. However, as the concentration of $\mathrm{ZnFe}_{2} \mathrm{O}_{4}$ increased, the intensity of the peaks due to $\mathrm{Ti}-\mathrm{O}$ in both rutile and anatase decreased significantly and new peaks were observed in the spectra. Significant changes were observed for $\mathrm{TiO}_{2} \cdot\left[\mathrm{ZnFe}_{2} \mathrm{O}_{4}\right]_{0.2}$, where two new, very intense peaks were observed at $460 \mathrm{~cm}^{-1}$ and $453 \mathrm{~cm}^{-1}$ (spectra not 
shown). Intensity of these new peaks increased with $x$, and became most prominent for $x=0 \cdot 5$, which indicates that they were probably originating from the dopant $\mathrm{ZnFe}_{2} \mathrm{O}_{4}$.

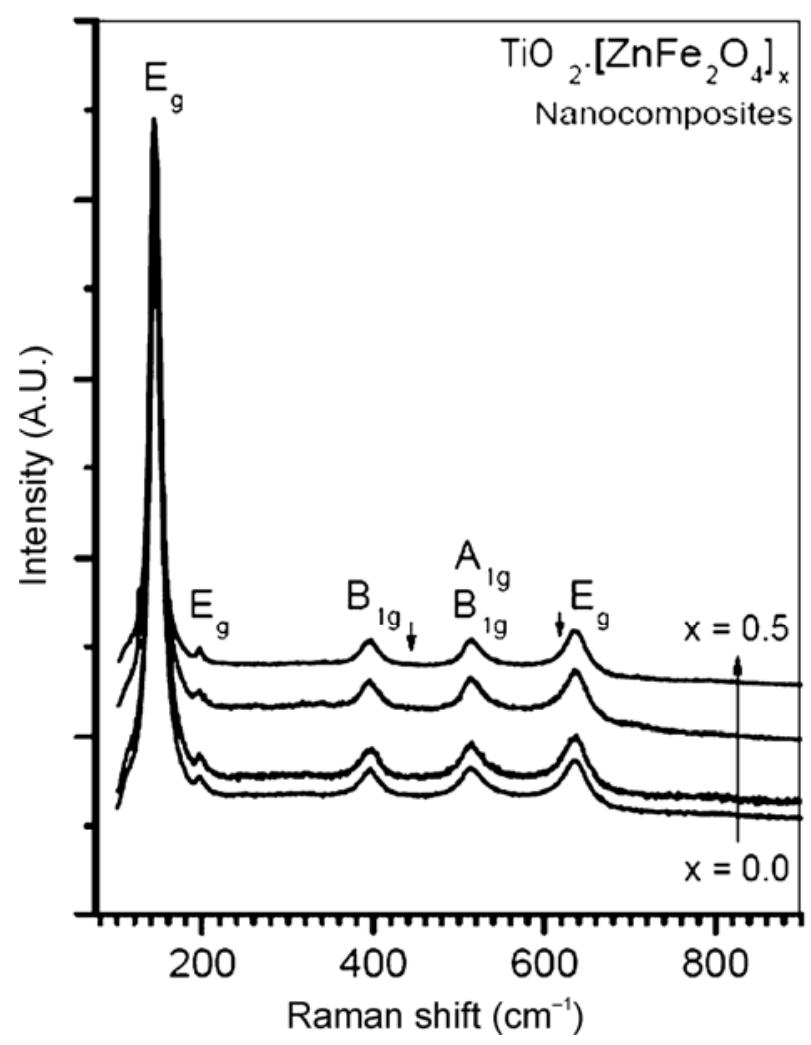

Figure 5. Raman spectra of $\mathrm{TiO}_{2} \cdot\left[\mathrm{ZnFe}_{2} \mathrm{O}_{4}\right]_{x}$ nanocomposites powders prepared by $\mathrm{CPH}$ showing the Raman modes for anatase phase. Arrows indicate the expected positions of rutile peaks.

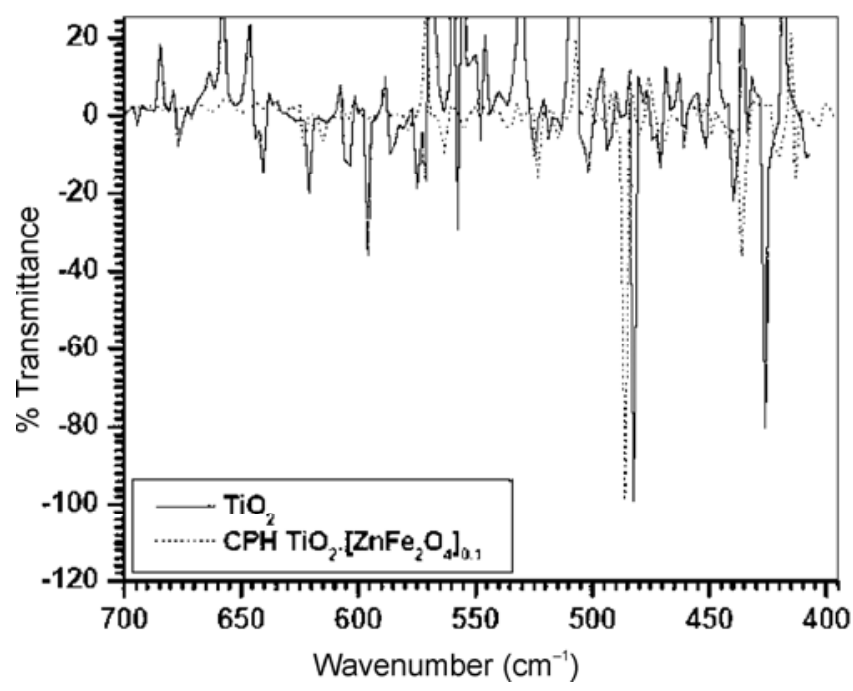

Figure 6. FTIR spectra of $\mathrm{CPH}$ synthesized $\mathrm{TiO}_{2} \cdot\left[\mathrm{ZnFe}_{2} \mathrm{O}_{4}\right]_{0 \cdot 1}$ and commercial $\mathrm{TiO}_{2}$.

\subsection{Photocatalytic activity}

The photocatalytic activity of the samples in response to visible light $(\lambda>420 \mathrm{~nm})$ irradiation was evaluated by the photooxidation of Congo Red (CR). Figure 7 shows the photocatalytic degradation of $\mathrm{CR}$ under visible light irradiation using: $\mathrm{TiO}_{2} \cdot\left[\mathrm{ZnFe}_{2} \mathrm{O}_{4}\right]_{0 \cdot 1}$ synthesized by $\mathrm{CPH}$, $\mathrm{TiO}_{2} \cdot\left[\mathrm{ZnFe}_{2} \mathrm{O}_{4}\right]_{0 \cdot 1}$ obtained from SSR route, a commercial $\mathrm{TiO}_{2}, \mathrm{CPH}$ synthesized $\mathrm{TiO}_{2} \cdot\left[\mathrm{ZnFe}_{2} \mathrm{O}_{4}\right]_{0 \cdot 1}$ in the absence of irradiation, and under irradiation but in the absence of any photocatalyst. No obvious degradation of CR was observed both for $\mathrm{CPH}$ synthesized $\mathrm{TiO}_{2} \cdot\left[\mathrm{ZnFe}_{2} \mathrm{O}_{4}\right]_{0.1}$ in the absence of irradiation, and under irradiation but in the absence of photocatalyst (see figure 7a). The percentages of visible light photo-degradation of $\mathrm{CR}$ with $\mathrm{CPH}$ synthesized $\mathrm{TiO}_{2} \cdot\left[\mathrm{ZnFe}_{2} \mathrm{O}_{4}\right]_{0 \cdot 1}$, commercial $\mathrm{TiO}_{2}$, and $\mathrm{TiO}_{2} \cdot\left[\mathrm{ZnFe}_{2} \mathrm{O}_{4}\right]_{0 \cdot 1}$ from SSR, after $150 \mathrm{~min}$ are about $90 \%$, $80 \%$ and $70 \%$, respectively. For all the three photocatalytic materials, the rate of degradation of $\mathrm{CR}$ was found to be of first order. The apparent rate constant $\left(k_{\text {obs }}\right)$ for the degradation process was calculated by a least-square regression of $\ln \left(C / C_{\mathrm{o}}\right)$ vs time and was found to be $0.016 \mathrm{~min}^{-1}$ for $\mathrm{CPH}$ synthesized $\mathrm{TiO}_{2} \cdot\left[\mathrm{ZnFe}_{2} \mathrm{O}_{4}\right]_{0 \cdot 1}$, $0.011 \mathrm{~min}^{-1}$ for the commercial $\mathrm{TiO}_{2}$, and $0.009 \mathrm{~min}^{-1}$ for $\mathrm{TiO}_{2} \cdot\left[\mathrm{ZnFe}_{2} \mathrm{O}_{4}\right]_{0 \cdot 1}$ from SSR.

The highest photocatalytic activity of the CPH synthesized NCs for visible light irradiation of $\mathrm{CR}$ was observed for $x=0 \cdot 1$ composition and beyond this it decreased with increasing molar concentration of $\mathrm{ZnFe}_{2} \mathrm{O}_{4}$. The possible reason for this is the fact that $\mathrm{ZnFe}_{2} \mathrm{O}_{4}$ as a

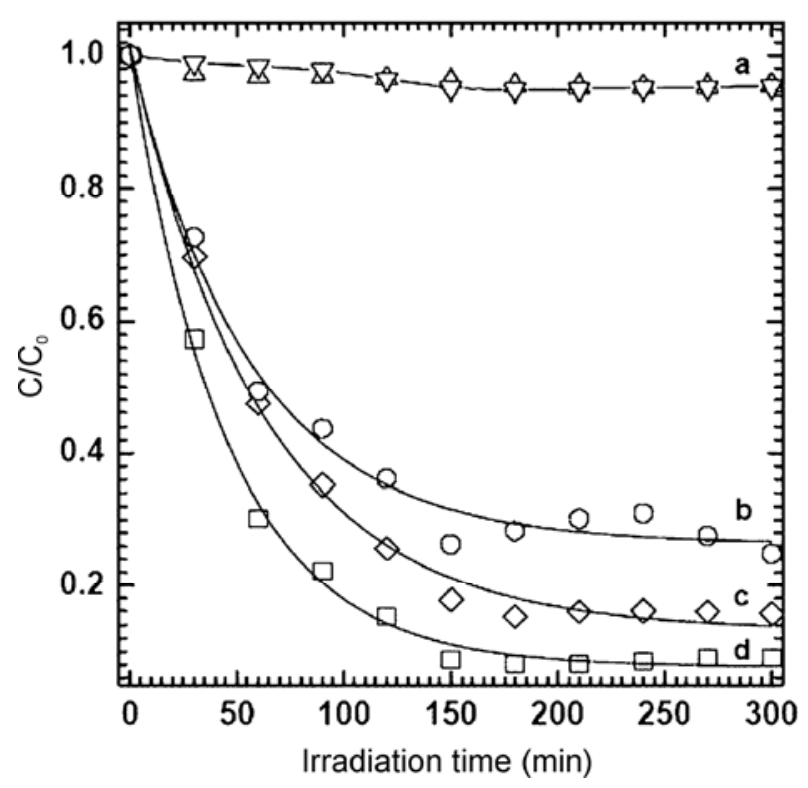

Figure 7. Visible light activated photocatalytic degradation of Congo Red: (a) CPH synthesized $\mathrm{TiO}_{2} \cdot\left[\mathrm{ZnFe}_{2} \mathrm{O}_{4}\right]_{0.1}$ in the absence of irradiation and under irradiation but in the absence of photocatalyst; (b) $\mathrm{TiO}_{2} \cdot\left[\mathrm{ZnFe}_{2} \mathrm{O}_{4}\right]_{0.1}$ from SSR; (c) a commercial $\mathrm{TiO}_{2} ;$, d) $\mathrm{TiO}_{2} \cdot\left[\mathrm{ZnFe}_{2} \mathrm{O}_{4}\right]_{0 \cdot 1}$ from $\mathrm{CPH}$. 
material apparently plays only a little role in the photocatalytic degradation of the dye under visible light because of its short photoactive lifetime (Wade 2005; Srinivasan et al 2006). Its primary functions are (i) to manipulate the bandgap of the composite in such a way that visible light photocatalysis is supported, and (ii) to suppress the undesired $e^{-} / h^{+}$recombination. For example, the useful part of the spectrum extends up to cut-off wavelengths of $420 \mathrm{~nm}$ and $445 \mathrm{~nm}$ (more towards the visible region) for $x=0.1$ and $0 \cdot 2$, respectively, in comparison to the $390 \mathrm{~nm}$ limit for pure $\mathrm{TiO}_{2}$ (Wade 2005; Srinivasan et al 2006). On the other hand, the $e^{-} / h^{+}$recombination, which hampers the photoactivity significantly as the particle size decreases, is also controlled by $\mathrm{ZnFe}_{2} \mathrm{O}_{4}$ doping. However, addition of $\mathrm{ZnFe}_{2} \mathrm{O}_{4}$ beyond a certain critical concentration (around $x=0 \cdot 1$ ) decreases the photoactivity, which is apparently due to the fact that it effectively lowers the concentration of the active part in the composite, the host $\mathrm{TiO}_{2}$, itself. Here, it is noteworthy that for higher doping $(x>0 \cdot 1)$, the observed decrease in photocatalytic activity in both CPH and SSR prepared samples does not seem to be directly associated with the anatase to rutile conversion as claimed by some authors (Srinivasan et al 2006). This is because no such conversion was observed in our XRD results (except perhaps for $x=0 \cdot 4)$. It may also be noted that the SSR prepared samples were mainly rutile, but still the sample with $x>0 \cdot 1$ showed significant photocatalytic activity. Thus, both the $\mathrm{TiO}_{2}$ phases can support photocatalysis, although anatase is more conducive than rutile in the photodegradation of CR (Wahi et al 2005). Liu et al

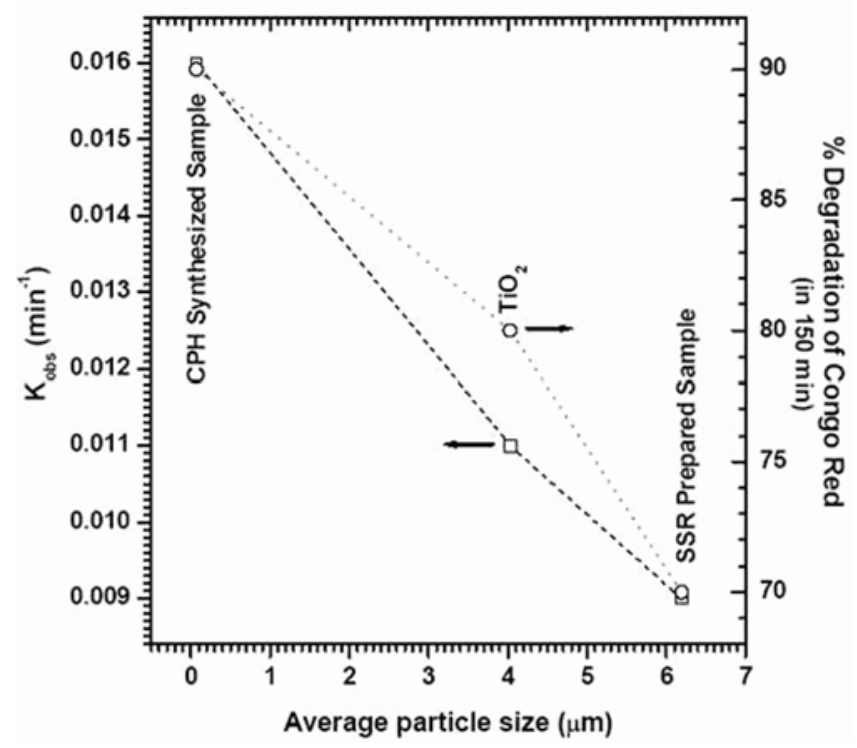

Figure 8. Variation of the rate constant (axis on left, squares) and percentage degradation (axis on right, circles) of Congo Red in correlation with the particle size for the composites with $x=0 \cdot 1$, and commercial $\mathrm{TiO}_{2}$ (Broken lines are shown just as a guide to eyes).
(2004) also reported that coexistence of anatase and rutile has higher efficiency for the degradation of Rhodamine $B$ than that with the anatase phase alone. However, the relationship between anatase-rutile phase composition, and the photocatalytic activity of the mixture, is not straightforward as it depends on a number of other factors too (Wahi et al 2005).

The above discussion clearly suggests that the enhanced photocatalytic activity of the NCs in comparison to that for the pure $\mathrm{TiO}_{2}$ may not be entirely due to $\mathrm{ZnFe}_{2} \mathrm{O}_{4}$ doping alone. Further, the observation that all $\mathrm{TiO}_{2} \cdot\left[\mathrm{ZnFe}_{2} \mathrm{O}_{4}\right]_{x}$ materials prepared by the SSR method showed lower photocatalytic activity as compared to the $\mathrm{CPH}$ synthesized NCs with similar compositions, and the commercial $\mathrm{TiO}_{2}$ points towards the significance of smaller particle size, or the effective surface area, in the enhancement of photocatalytic activity. From the particle size analysis, it was evident that $\mathrm{CPH}$ synthesis had produced smaller particles (size $\leq 86 \mathrm{~nm}$ ) than that produced by the SSR route $($ size $\leq 6.5 \mu \mathrm{m})$. The commercial $\mathrm{TiO}_{2}$ had a particle size $\leq 5.0 \mu \mathrm{m}$ (data provided by the supplier). Moreover, for the composition with $x=0 \cdot 1$ synthesized by $\mathrm{CPH}$ (the one showing highest photocatalytic activity), the average particle size was only $71.0 \mathrm{~nm}$, as compared to average sizes of 6.19 and $4.03 \mu \mathrm{m}$, respectively, for similar composition prepared by SSR and the commercial $\mathrm{TiO}_{2}$. Therefore, the lower photoactivity of SSR prepared samples as compared to pure $\mathrm{TiO}_{2}$ also, may be attributed to the smaller particle size of the latter. If bandgap modification only was responsible, the SSR prepared material with $x=0 \cdot 1$ should have shown higher photocatalytic activity (because of the $\mathrm{ZnFe}_{2} \mathrm{O}_{4}$ doping) as compared to that shown by the pure $\mathrm{TiO}_{2}$. Obviously, in the $\mathrm{CPH}$ synthesized $\mathrm{NC}$ with $x=0 \cdot 1$ also, further enhancement in the photocatalytic activity as compared to the SSR sample with similar composition is because of its reduced particle size. These results are in very good agreement with those obtained by Wahi et al (2005), who have reported that the photodegradation of $\mathrm{CR}$ by pure $\mathrm{TiO}_{2}$ nanostructures (nanoparticles and nanorods) largely depends on the particle size and effective surface area of the catalyst. It is also possible to see from figure 8 that the visible light photodegradation of $\mathrm{CR}$, both in terms of percent degradation as well as the calculated rate constants $\left(k_{\text {obs }}\right)$, correlates nicely with the particle size.

Based on these results, it may be concluded that in the $\mathrm{TiO}_{2} \cdot\left[\mathrm{ZnFe}_{2} \mathrm{O}_{4}\right]_{x}$ nanocomposite materials, photosensitization is the mechanism primarily responsible for improved photocatalytic activity. For a given amount of the material, smaller particle size is directly related to larger effective surface area available to the dye molecules to get adsorbed on the catalyst particles. Once adsorbed on the surface, the dye molecules start utilizing the visible light (wavelength $<500 \mathrm{~nm}$ for $\mathrm{CR}$ ) to get photochemically excited, which leads to the degradation of other molecules by the process of photosensitization. 


\section{Conclusions}

Two mechanisms govern the $\mathrm{TiO}_{2}$ mediated photocatalysis process. The first depends upon the bandgap of the semiconductor, whereas the second, on its active surface area. By suitable doping, the bandgap can be modified in such a way that visible light photocatalysis is supported. On the other hand, particles with smaller size can be produced by using appropriate method of synthesis. Taking into consideration these important aspects, $\mathrm{TiO}_{2} \cdot\left[\mathrm{ZnFe}_{2} \mathrm{O}_{4}\right]_{x}$ $(x=0.0$ to 0.5$) \mathrm{NCs}$ with average particle size of $72.4 \mathrm{~nm}$ were synthesized by the method of CPH. The samples were characterized using SEM, XRD, particle size analyzer, and Raman and FTIR spectroscopy. Another set of samples with similar compositions was prepared by SSR route, and characterized using the same techniques. Average particle size of these samples was about $3.0 \mu \mathrm{m}$.

Visible light photocatalytic activity of the samples was tested for the degradation of Congo Red. Maximum photodegradation was observed for the $\mathrm{CPH}$ synthesized NC with $x=0 \cdot 1$. The fact that more doping does not increase photocatalytic degradation by the composites, although it does extend the cut-off wavelength further in the visible region, indicates that the enhancement is not solely due to doping. CPH synthesized NC (particle size, $71 \mathrm{~nm}$ ) showed higher photoactivity than the one prepared by SSR method (particle size, $6 \cdot 19 \mu \mathrm{m}$ ), indicating towards the role of smaller particle size in increasing photocatalytic activity. Another comparison between the results for pure $\mathrm{TiO}_{2}$ (particle size, $4.03 \mu \mathrm{m}$ ) with those for SSR composites leads to the conclusion that reduced particle size is primarily responsible for the improved photodegradation. It can, therefore, be concluded that the $\mathrm{CPH}$ synthesized nanocomposites lead to improved photocatalytic activity in the degradation of Congo Red because the smaller particle size provides larger effective surface area, which supports the process of degradation by photosensitization.

\section{References}

Boulc'h F, Schouler M -C, Donnadieu P, Chaix J -M and Djurado E 2001 Image Anal. Stereol. 20157

Bumpas J A, Tricker J, Andrzejewski K, Rhoads H and Tatarko M 1999 J. Chem. Ed. 761680

Busani T and Devine R A B 2005 Semicond. Sci. Technol. 20 8705

Cheng P, Li W, Zhou T, Jin Y and Gu M 2004 J. Photochem. Photobiol. A: Chemistry 16897

Dung N T, Khoa N V and Herrmann J M 2005 Int. J. Photoenergy 0711

Ghosh M and Raychaudhuri A K 2007 Nanotechnology 18 115618

Habibi M H, Esfahani M N and Egerton T A 2007 Int. J. Photoenergy, Article ID 13653

Khan M A, Jung H -T and Yang O -B 2006 J. Phys. Chem. B110 6626

Li L, Chu Y and Liu Y 2007 Nanotechnology 18105603

Liu G -G, Zhang X -Z, Xu Y -J, Niu X -S, Zheng L -Q and Ding X -J 2004 Chemosphere 551287

Srinivasan S S, Wade J and Stefanakos E K 2006 J. Nanomater., Article ID 45712

Wade J 2005 An investigation of $\mathrm{TiO}_{2}-\mathrm{ZnFe}_{2} \mathrm{O}_{4}$ nanocomposites for visible light photocatalysis, M.Sc. Thesis, College of Engineering, University of South Florida, USA

Wahi R K, Yu W W, Liu Y, Mejia M L, Falkner J C, Nolte W and Colvin V L 2005 J. Mol. Catal. A: Chemical 24248

Yuan Z -H and Zhang L -D 2001 J. Mater. Chem. 111265

Zhang W F, He Y L, Zhang M S, Yin Z and Chen Q $2000 \mathrm{~J}$. Phys. D: Appl. Phys. 33912 